\title{
Effect of a low cost diet on the cotton leaf worm, Spodoptera littoralis nucleopolyhedrosis virus pathogenicity and sterile insect technique
}

\author{
Waheed A. A. Sayed ${ }^{1 *} \mathbb{D}$, Alexandra El-Helaly ${ }^{2}$, Zakia A. Jamal ${ }^{3}$ and Helmy El-Bendary ${ }^{4}$
}

\begin{abstract}
Background: Mass rearing cost of Spodoptera littoralis (Boisd.) (Lepidoptera: Noctuidae) is one of the critical methods for the successful utilization of Baculovirus pathogenicity and sterile insect technique (SIT). Effectiveness of both SIT and S. littoralis Nucleopolyhedrosis Virus (SpliNPV) was assessed in response to plant-based diet and substitution of agar with commercial sources of gelling components as feed.

Results: Pupal and adult recoveries produced by castor bean leaves were significantly high, followed by the agarbased diet. Moreover, larval durations were significantly prolonged for (starch + gelatin)-based diet than the other dietary diets. Obviously, SpliNPV pathogenicity against the larvae reared on (starch + gelatin)-based diet was 2.5 and 2 times higher than those reared on castor leaves and agar-based diet, respectively. Contrary to expectation, the sterility doses of male moths produced by castor leaves and agar-based diet were relatively similar.

Conclusion: The findings suggest that the lowest cost diets (starch + gelatin)-based diet could be used effectively for increasing the SpliNPV pathogenicity, while either castor leaves or agar-based diet could be considered as a promising choice for SIT program.
\end{abstract}

Keywords: Lepidopteran-diet interaction, Gelling agents, Bioassay, Baculovirus infectivity, Male sterility

\section{Background}

The cotton leaf-worm, Spodoptera littoralis (Boisd.) (Lepidoptera: Noctuidae) is an economic pest of numerous cultivated plants in many regions. It is considered a serious polyphagous pest in different countries, attacking many vegetable and field crops worldwide (El-Helaly et al. 2020). Use of Baculovirus and Sterile Insect Technique (SIT) could be effective strategies against $S$. littoralis to substitute chemical pesticides that have diverse impacts on the environment and its fauna (Sayed and ElHelaly 2018). Facilitating S. littoralis in a low-cost diet is one of the key tasks for the successful use of SIT (Calkins and Parker 2021) and also Baculovirus production

\footnotetext{
*Correspondence: waheed.sayed@eaea.org.eg

${ }^{1}$ Biological Application Department, Nuclear Research Center, Atomic

Energy Authority, Cairo 11787, Egypt

Full list of author information is available at the end of the article
}

(Mabrouk et al. 2001). S. littoralis Nucleopolyhedrosis virus (SpliNPV) is belonging to Baculovirus that has a high pathogenic specificity on only $S$. littoralis making it highly safe environmental control agent (Elmenofy et al. 2020). Pathogenicity of NPV may be improved if any factor goes in line with the insect host immunity that could be influenced by modifying the artificial diets (Chen et al. 2018). Additionally, the susceptibility of lepidopteran larvae to viral infections could be altered by various diets (Shikano et al. 2010). Recently, SIT is widely applied against various pest insects in many regions (Dyck et al. 2021). It depends on releasing the sterile adults of targeted insect previously irradiated with gamma or X-ray into the field. Sterile moths should be facilitated in high numbers with a good quality to suppress the population effectively (Hendrichs et al. 2002). The associate cost, time, space and ingredients availability of insect food are the tools for improving the insect rearing facilities 
(Assemila et al. 2012). Many artificial diets have been known to rear S. littoralis species; however, developing these artificial diets are continuously required to optimize the reared insect for SpliNPV production and SIT program. Larval diet was recently applied, depends on agar ingredient as gelling agent, is a very expensive and imported product in the most countries. Alternative ingredients or decreasing their significant amount by commercial and cheap alternative gelling sources will be useful. Therefore, this trial aimed to evaluate gelatin and starch ingredients as alternative gelling sources for rearing S. littoralis, and it does indeed have a multivariate optimization perspective, taking into account of Baculovirus production and SIT performance, as well as dietary cost.

\section{Methods}

\section{Test insect}

A colony of $S$ littoralis was maintained under laboratory conditions at $25 \pm 2{ }^{\circ} \mathrm{C}$ and $65 \% \pm 10$ R.H. Fullformed pupae were supplied in the adult rearing cage $(40 \times 20 \times 10 \mathrm{~cm})$ with small cups containing pieces of cotton wool soaked with $10 \%$ sugar for feeding the emergent moths. Egg-masses were collected daily and transferred to glass gars $(1600 \mathrm{cc})$, covered with muslin cloth, until they hatch. The newly hatched larvae were transferred to rounded plastic bowls $(70 \times 15 \mathrm{~cm})$ with castor bean leaves, Ricinus communis for feeding and covered with both muslin cloths until pupating.

\section{Larval feed substrate}

Two gelling agents, starch and gelatin powders (local market), were used to replace Agar Agar powder (landor,
Co Ltd, USA), used for semi-artificial diets described by Shorey and Hale (1965). Five semi-artificial diets were tested: agar-based diet (A), starch-based diet (S), gelatin-based diet (G), starch + gelatin based diet (SG) and agar + starch + gelatin-based diet (ASG) were tested alongside the castor leaves-based diet (CL) (Table 1). One hundered nwely hatched larvae, with 5 replicates, were used. Reared larvae were weighted during their development at the age of 5, 9 and 13 days, using a laboratory balance. Five replicates, with 10 larvae each treatment, were weighted. Resultant pupae from each treatment were collected daily, sexed and stored in waxed paper cups on moist sawdust and covered with muslin cloth. Five replicates of newly formed pupae (10 pupae each) were collected at the same day of formation and weighted at the 5 days old.

\section{Bioassay of insect diet and SpliNPV production}

Local isolate of SpliNPV was used in the bioassay experiments. The pathogenicity was evaluated on the 2nd instar larvae of S. littoralis. Eight different virus concentrations from $1 \times 10^{2}$ to $1 \times 10^{9} \mathrm{BIPs} / \mathrm{ml}$. (polyhedral inclusion bodies (PIB) $/ \mathrm{ml}$ ) were prepared from the stock concentration that was $2.3 \times 10^{9} \mathrm{PIB} / \mathrm{ml}$. The interaction of NPV pathogenicity and dietary larvae was referred as a mortality-response andwas calculated, accoeding to the bioassy standard method previously described (Sun et al. 2004), namely $1 \mathrm{ml}$ of each concentation was spread on the surface special plate $(20 \times 10 \times 3 \mathrm{~cm})$ divided to 50 cells containing $50 \mathrm{ml}$ of the tested semi artificial diets. Distilled water was used for untreated control experiments. Then, 50 larvae were allowed to feed onto the died until death

Table 1 Ingredients of 6 tested diets based on gelling agent rearing Spodoptera littoralis larvae as compared to the castor plant diet and their cost study

\begin{tabular}{|c|c|c|c|c|c|c|}
\hline Ingredients & $\mathrm{CL}$ & $A$ & ASG & SG & $S$ & G \\
\hline Agar (gm.) & 0 & 60 & 30 & 0 & 0 & 0 \\
\hline Starch (gm.) & 0 & 0 & 35 & 75 & 150 & 0 \\
\hline Gelatin (gm.) & 0 & 0 & 35 & 75 & & 150 \\
\hline White Kidney Bean (gm.) & 0 & 1000 & 1000 & 1000 & 1000 & 1000 \\
\hline Brewer yeas (gm.) & 0 & 150 & 150 & 150 & 150 & 150 \\
\hline Ascorbic acid (gm.) & 0 & 15 & 15 & 15 & 15 & 15 \\
\hline Sorbic Acid (gm.) & 0 & 5 & 5 & 5 & 5 & 5 \\
\hline Methyl benzoate (gm.) & 0 & 9.5 & 9.5 & 9.5 & 9.5 & 9.5 \\
\hline Formaldehyde (ml.) & 0 & 10 & 10 & 10 & 10 & 10 \\
\hline Distilled water (ml) & 0 & 2000 & 2000 & 2000 & 2000 & 2000 \\
\hline Castor plant (gm.) & 1000 & 0 & 0 & 0 & 0 & 0 \\
\hline \multicolumn{7}{|l|}{ Economic impact } \\
\hline Gel cost/kg diet (US \$) & 0.0 & 2.4 & 1.41 & 0.42 & 0.15 & 0.75 \\
\hline Cost saving (\%) & $100 \%$ & - & 41.25 & 82.5 & 93.8 & 68.8 \\
\hline
\end{tabular}


or pupation. Each treatment was repeated in 5 replicates. Mortality responses in each treatment of larvae, fed on different artificial diets, were daily recorded.

\section{Irradiation technique}

Full grown male pupae of $S$. littoralis before emergence ( $24 \mathrm{~h}$ ) were irradiated by the sub sterlizing doses 150, 200 and 250 Gy (Gy), using Cobalt 60 gamma cell located at the Nuclear Research Cener, at a dose rate of $0.60 \mathrm{~Gy} /$ min. Effect of gamma irradiation on male sterility was evaluated based on egg hatch. Newly emerged male moths resulted from irradiated pupae were paired with un-irradiated females. Each pair was introduced into 75 cc cylindrical glass cage internally lined with papers as an ovipositional site and covered with muslin cloth. Cages were supplied by $10 \%$ sugar solution as feed. The experiment was conducted with 15 replicates per treatment. Daily deposited eggs of irradiated and un-irradiated treatments were collected (fecundity), counted, and kept 5 days for calculating the parentage of hatched eggs (fertility). Sterility index was calculated according to the Toppozada et al. (1966) formula: \% sterility $=[1$ - $(\mathrm{Fu} \times \mathrm{FeI} / \mathrm{Fc} \times \mathrm{Fec})] \times 100$, where: $\mathrm{Fu}=$ fecundity of un-irradiated treatment; $\mathrm{FeI}=$ fertility of irradiated treatment; $\mathrm{Fc}=$ fecundity of control; and $\mathrm{Fec}=$ fertility of control.

\section{Statistical analysis}

Biological and biochemical studies were examined by one way analysis of variance (ANOVA) technique, means were analyzed by Tukey's multiple range test, when the $(p<0.01)$, the ANOVA statistics are significant. Mortality response of $S$. littoralis larvae of several diets were analyzed, using Probit analysis, slope. $\mathrm{LC}_{50}$ was calculated according to Finney (1971). The reproduction rate averages were calculated by the model designed by Regniere et al. (2012), the trendline labels were created by Excel 2010.

\section{Results}

The cost impact of modified diets was presented in Table 1 the Gel cost $/ \mathrm{kg}$ diet for each diet which were lower (0.0, 0.15 and 0.42 US \$) for CL, S and SG diets, respectively than $(0.75,1.41$ and 2.4 US $\$$ ) for G, ASG and A diets, respectively. Moreover, substituting full and partial amount of agar by gelatin and starch reduced the diet cost by $82.5 \%$ and 41.25 , respectively per one kilogram of diets (Table 1).

Pupae and adults production were significantly different from the tested larval diets $(p<0.001)$ as shown in Fig. 1. No pupae was produced by starch-based diet (S) and gelatin-based diet (G), while the percentage of pupal recovery of (starch + gelatin)-based diet (SG) was lower

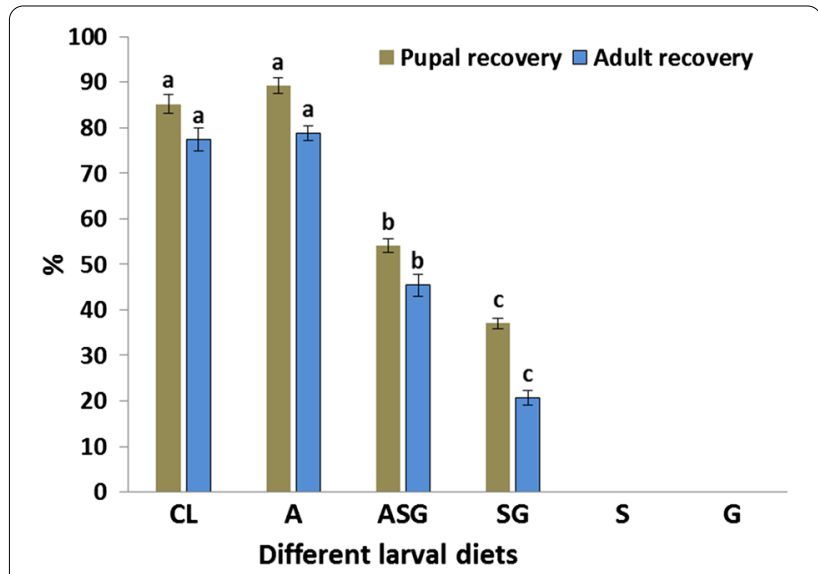

Fig. 1 Percentages of pupal and adult recovery produced by 6 different larval diets of Spodoptera littoralis

Table 2 Weight averages of three ages (day) of larvae and 24 age pupae produced from 4 different larval diets of Spodoptera littoralis

\begin{tabular}{llllll}
\hline Diets & \multicolumn{2}{l}{$\begin{array}{l}\text { (Avg.) larval weight (mg/larvae) at } \\
\text { different days }\end{array}$} & (Avg.) Pupal weight \\
\cline { 2 - 4 } & $\mathbf{5}$ days & \multicolumn{2}{c}{$\mathbf{9}$ days } & $\mathbf{1 3}$ days & \\
\hline $\mathrm{CL}$ & $190.7 \pm 2.0 \mathrm{a}$ & $500.6 \pm \mathrm{a}$ & $700.4 \pm 10.3 \mathrm{a}$ & $324.5 \pm 1.9 \mathrm{a}$ \\
$\mathrm{A}$ & $175 \pm 1.2 \mathrm{~b}$ & $433 \pm 2.3 \mathrm{~b}$ & $625.1 \pm 12.1 \mathrm{~b}$ & $322.3 \pm 3.1 \mathrm{a}$ \\
$\mathrm{ASG}$ & $150 \pm 1.7 \mathrm{C}$ & $381 \pm 2.5 \mathrm{c}$ & $530.2 \pm 1.8 \mathrm{C}$ & $300.5 \pm 2.1 \mathrm{~b}$ \\
$\mathrm{SG}$ & $122 \pm 2.3 \mathrm{~d}$ & $250 \pm 3.2 \mathrm{~d}$ & $400.0 \pm 2.5 \mathrm{~d}$ & $250.4 \pm 3.2 \mathrm{c}$ \\
\hline
\end{tabular}

(39.4\%) than those were recorded (61.8, 85.2 and $89.2 \%)$ $\left(F_{(3,16)}=170.8, p<0.001\right)$ of by (agar + starch + gelatin)based diet (ASG), agar-based diet (A) and castor leavesbased diet (CL), respectively. The same trend was noticed in the adult recovery whereas the highest percentage of adult moths was produced by A diet (78.8\%) followed by CL diet (75.21\%), ASG diet (45.4) and SG diet (20.6), $\left(F_{(3,16)}=148.29, p<0.001\right)$.

The data in Table 2 showed that the weight of larvae fed on diet CL was significantly heavier than those fed on artificial diets, while the lowest larval weight was recorded in the ASG and SG diets at the periods of 7 days $\left(F_{(3,16)}=109.1\right), 10$ days $\left(F_{(3,16)}=130.1\right)$ and 13 days $\left(F_{(3,16)}=158.4\right)$ with $p<0.001$. In the same table, the pupal weight for castor $\mathrm{CL}$ diet and agar-based A diet were significantly heavier than those fed on ASG diet and SG diet $\left(F_{(3,16)}=139.5, p<0.001\right)$.

Data in Fig. 2, showed the duration of larvae fed on A, ASG and SG diets was significantly prolonged than those fed on CL diet $\left(F_{(3,16)}=121.4, p<0.001\right)$. However the duration of pupae resulted from larvae fed on $\mathrm{CL}$ and $\mathrm{A}$ 


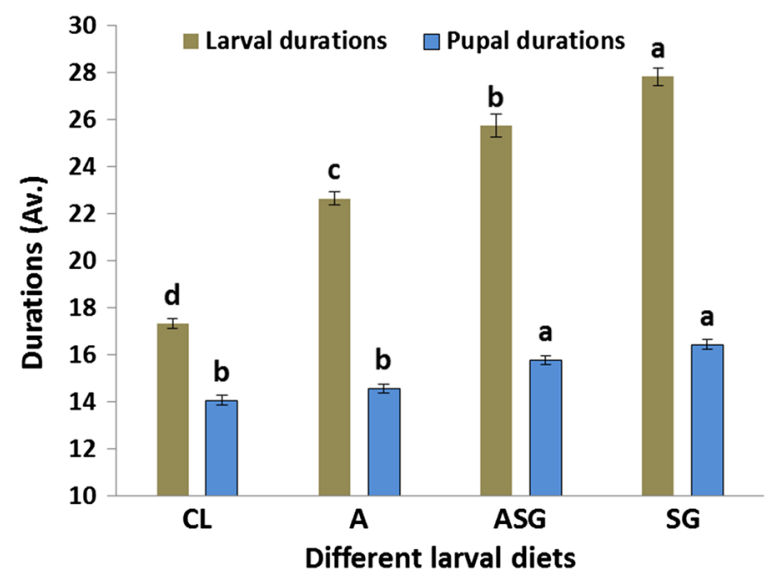

Fig. 2 Averages of larval and pupal durations in response to using 4 different diets for rearing Spodoptera littoralis larvae

were significantly lower than those fed on ASG and SG $\operatorname{diets}\left(F_{(3,16)}=24.8, p<0.001\right)$.

Impact of different diets, as insect feed on SpliNPV pathogenicity, is presented in Fig. 3. The date indicated that a high pathogenicity $\left(\mathrm{LC}_{50}=3.8 \times 10^{3} \mathrm{PIB} / \mathrm{ml}\right)$ was recorded of the larvae fed on SG diet, followed by those fed on ASG diet $\left(\mathrm{LC}_{50}=3.9 \times 10^{4} \mathrm{PIB} / \mathrm{ml}\right)$, A diet
$\left(\mathrm{LC} 50=1.4 \times 10^{6} \mathrm{PIB} / \mathrm{ml}\right)$ and $\mathrm{CL} \operatorname{diet}\left(\mathrm{LC}_{50}=1.3 \times 10^{7}\right.$ $\mathrm{PIB} / \mathrm{ml})$. Data revealed that the mortality of larvae fed on the diet contains starch and gelatin was greater ( 2 and 2.5 times) as compared to those fed on agar-based diet and castor plant in response to SpliNPV infection. The results revealed that gelling agents may be has important role for insect immunity or susceptibility against SpliNPV infection in particular the low concentrations from $1 \times 10^{2}$ to $10^{5} \mathrm{PIB} / \mathrm{ml}$, the pathogenicity of virus was greatly varied by the different of larval diets, which has been expressed as larval mortality (Fig. 5), and also the changes of larval color (Fig. 4), namely the infection was high in the larvae fed on SG diet (Fig. 4d) followed by ASG diet (Fig. 4c), while the larvae fed on A diet (Fig. 4b) and CL diets (Fig. 4a) exhibited low virus infection.

The sterility of the irradiated male moth induced by gamma irradiation which resulted from $C L$ and $A$ is analyzed (Fig. 5). The ASG and SG were ruled out because they were of too low quality to use in SIT program as observed in the previous experiments. Full sterility (100\%) were showed for irradiated males with the dose rate 250 Gy of both CL and A diets, however, irradiated males fed on CL diet exhibited less sterility (55.2 and 73.4\%) than that resulted from A diet (60.5 and 78.1\%) when exposed to the sub-sterilizing doses 100, $150 \mathrm{~Gy}$,

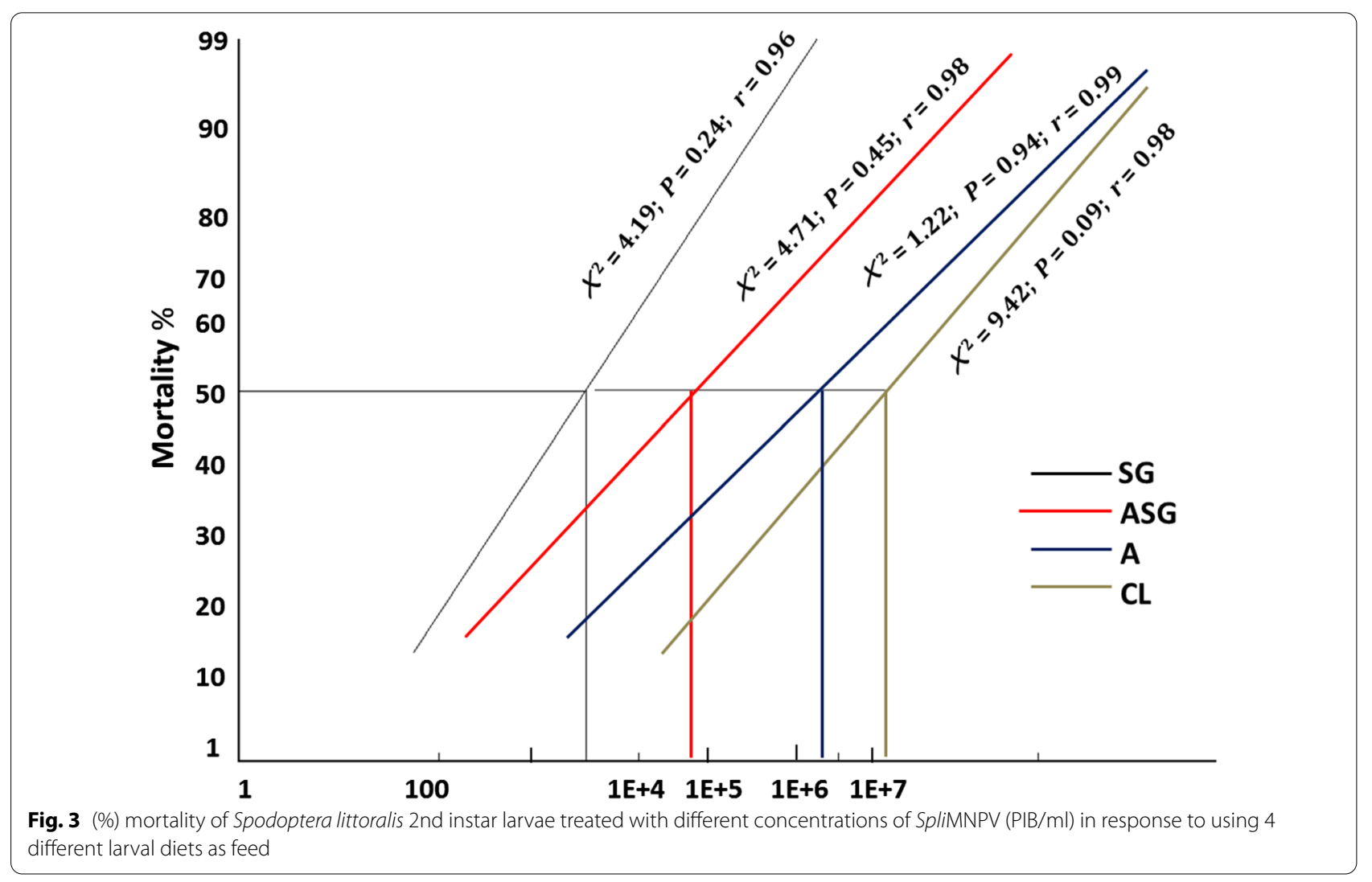



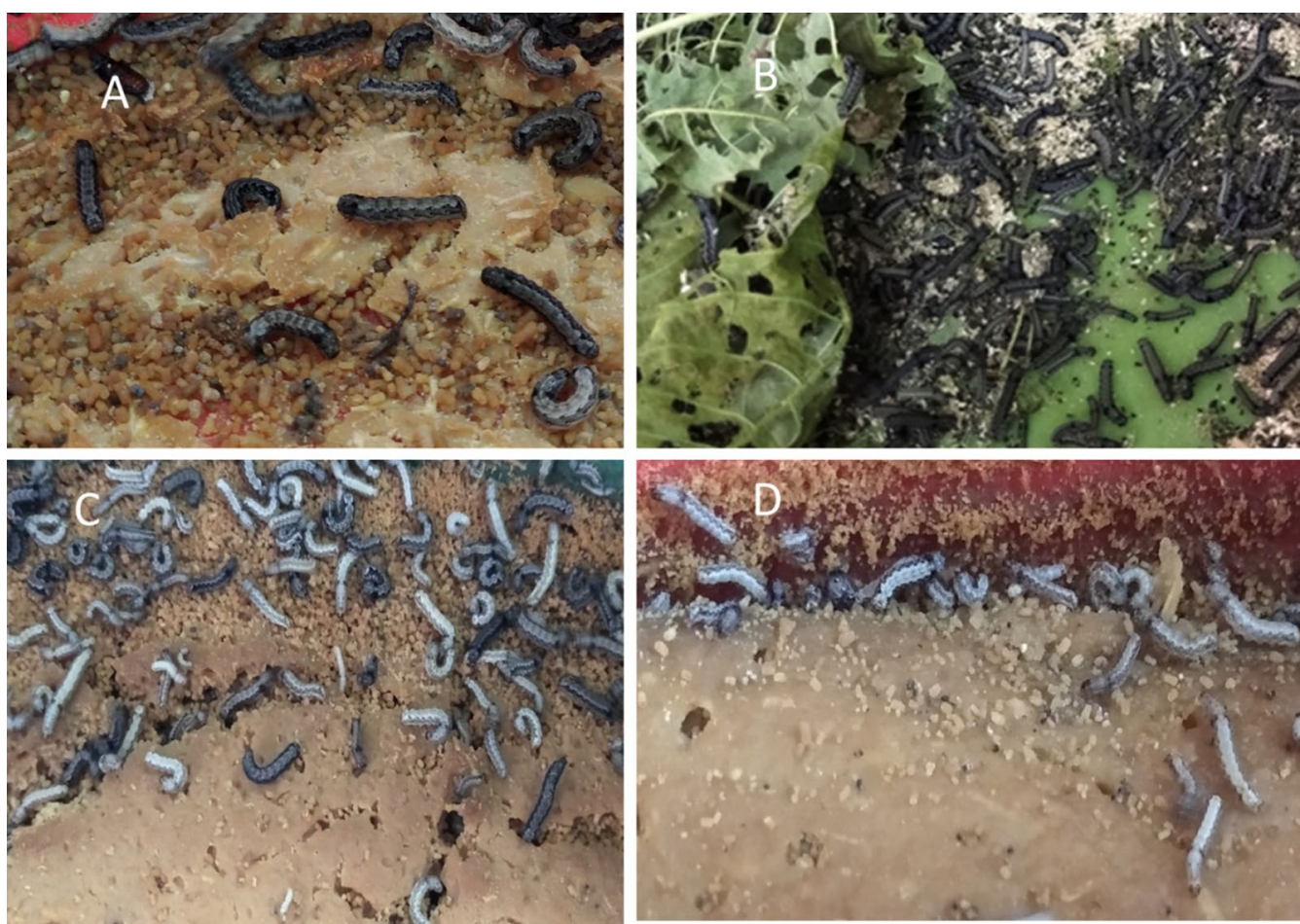

Fig. 4: 4th and 5 th instar larvae of Spodoptera littoralis treated with low concentration $\left(1 \times 10^{2} \mathrm{PIB} / \mathrm{ml}\right)$ SpliMNPV as 2 nd instar in response to using 4 different larval diets as feed, CL (b), A (a), ASG (c) and SG (d)

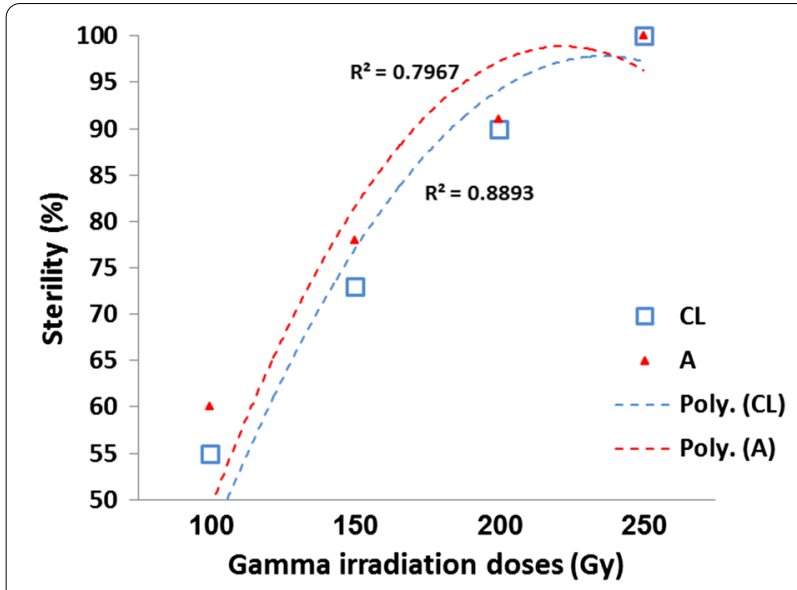

Fig. 5 Percentages of sterility of male adults previously irradiated as pupae with different doses of gamma radiation in response to castor plant $(\mathrm{CL})$ and semi-artificial diets based-agar (A) as larval feed

respectively. Moreover, the sterility was relatively similar (90.2 and 91.1\%) of those fed on CL and A diets, respectively in the case of $200 \mathrm{~Gy}$.

\section{Discussion}

The artificial diets of rearing various lepidopteran insect pest have been promoted successfully, but the most of them have been excluded for using in SIT due to their high cost Marec and Vreysen (2019). Accordingly, replacement of agar with less expensive ingredient such as starch and/or gelatin from the larval diet lead to reduce the mass rearing cost which has been considered one of the key success factors for the implementation of the SITprogram. In the present study, substituting full and partial amount of agar by both gelatin and starch reduced the diet cost by five and twofolds, respectively per one kilogram of diets. Notwithstanding, the evidence that ether gelatin or starch did not succeed in rearing $S$. littoralis larvae when used individually as substitute of agar, starch was used to as gelling agent by Abbasi et al. (2007) on Helicoverpa armigera and by Amer (2015) on Earias insulana. Furthemore, gelatin was used sucsessfuly by Pascacio-Villafán et al. (2020) for Anastrepha ludens rearing. Result revealed that the dietary of castor plant and the agar-based diet generated heavier larvae and pupae than those containing (starch + gelatin). Furthermore, the larvae fed on castor plants result in shorter duration for pupae than those fed on the artificial diets. These results of larval survival differentials may be attributed to two factors, improved health due to a protective 
effect or worsened health due to physiological changes (Jiang et al. 2010). It is likely that the castor plant diet and the agar-based diet were of a higher yield than the other tested diets; these current results coincide with the previous studies of the demographic response in Lepidopteran insect to imbalanced nutrients of dietary larvae (Carey 2001). In contrast to the present findings, insignificant differences were found for both survival and production of $S$. littorals using two diets containing either starch or agar ingredients (Sorour et al. 2011).

Insect biochemical composition and enzymatic activity may be affected as a result of supplying or lacking a small amount of nutrients and the P: $\mathrm{C}$ ratio intake by dietary insect. Additionally, the changes of diet physicochemical such as buffering capacity, $\mathrm{pH}$, and redox potential may influence on insects gut conditions and/ or made of the food is nutritionally suboptimal required (Johnson and Felton 1996). The most striking feature of these data is that the light weight and extended duration of larvae after dietary feeding could be attributed to the impact of the tested gelling agent agar, starch and gelatin that might cause deleterious insect physiology and different biochemical levels. These gelling agents consist of different protein and carbohydrate ratios that could change the intake of $P: C$ and have a wide range of micronutrients, such as potassium, sodium, calcium and ferric, many of which have physiological processes (Reinecke 2013). These results are consistent with those of Lee et al. (2003), Thompson and Redak (2005) and Nash and Chapman (2014) who concluded that the abandonment of P: C regulations had a negative impact on the development of insects in response to unbalance of macronutrients in the S. littoralis, Manduca sexta (Linnaeus 1763) and Ceratitis capitata (Wiedemann) diets, respectively. In contrast, growth and survival were mostly unchanged by protein and carbohydrate balance in insect diets (Silva et al. 2017).

Results of SpliNPV pathogenicity indicated that the virus actions were varying by the different dietary larvae, whereas it was greatly produced by the larvae reared on (starch + gelatin)-based diet, whilst the larvae reared on castor plant had the lowest susceptible level. These varying of viral pathogenicity may go into the interaction between larval dietary nutrients and insect immunity. The current findings go in line with those of Povey et al. (2104) who found that a low P: C ratio in the larval diet of Spodoptera exempta increased the viral pathogenicity. The potential resistance mechanism of insect to Baculovirus, in response to larval diet was initially reported by Lee et al. (2003) who found that the susceptibility to viral infection and relatively impaired immune function of low dietary P: C ratio was greater than that of high dietary P: $\mathrm{C}$ ratio. The loss of the potency of the
SpliNPV in the different diets was associated with the theory of the direct effects of insect feed intake on viral pathogenicity and insect growth rate (Chen et al. 2018). Another possible hypothesis is that the dietary compositions may induce inhibition of apoptosis in infected cells, which prevents inflammatory reactions and extinguishes the reactive oxygen species (ROS) that have caused differences in insect viral pathogenicity (Hay et al. 2020). It is known that insect immune system depends on rapid apoptosis of infected Baculovirus cells generating ROS to avoid the viral premature cell multiplication (Circu and Aw 2010). The present results concerning larval susceptibility against SpliNPV due to different diets as feed is consistent with Hoover et al. (2000) who concluded that high ROS levels were generated in the midgut lumen of Heliothis virescens (Fabricius) larvae reared on cotton leaf as compared to those reared on artificial diet.

Even though the (starch + gelatin)- based diets is cheaper than that contains agar-based diet, these diets did not produce sufficient numbers of moth to be considered as candidate diets for S. littoralis mass rearing in SIT program. The different sterility profiles of the irradiated males resulted from the two larval diets, castor plant and agar-based diet are given in the line of evidence supporting the hypothesis that nutritional factor rendering insect to be tolerant or sensitive for irradiation treatments. This trend, evident in the current study, was particularly striking in dietary-sterilizing interaction studies. Unlike females and males have little or no response to radiation-dietary interaction (Carey et al. 2001) but, sterility trajectory of male adults was influenced by nutrients encountered during the developmental stages (Astuti et al. 2020).

\section{Conclusions}

The successful use of SIT for S. littoralis management could be achieved by developing the economic value of insect mass rearing. Moreover, high SpliNPV infectivity might be induced by adjusting the larval diet. Commercial and cheap ingredients, gelatin and starch in substitution for agar have been assessed as gelling agent for $S$. littoralis dietary larvae. Although, the larvae exhibited developmental plasticity and were capable of successfully using the novel gelling ingredients, the deleterious effect of certain biological properties was observed. The results indicated that the quality and quantity of $S$. littoralis were inhibited with the use of gelatin and starch as gelling agent as compared to agar ingredients. The results suggested that the starch and gelatin-based diet has provided insight into successful SpliNPV production, while the effective diets, castor plant and agar-based diet could be considered as remarkably useful for SIT program. 


\begin{abstract}
Abbreviations
SpliMNPV: Spodoptera littoralis Multiple nucleopolyhedrosis virus; PIB: Polyhedral inclusion bodies; $\mathrm{LC}_{50}$ : Median lethal concentration or lethal concentration 50; SIT: Sterile insect technique; (A): Semi-artificial diet contains agar ingrediant as gelleing agent; (S): Semi-artificial diet contains starch ingrediant as gelleing agent; (G): Semi-artificial diet contains gelatin ingrediant as gelleing agent; (SG): Semi-artificial diet contains (starch + gelatin) ingrediants as gelleing agent and (ASG): semi-artificial diet contains (agar + starch + gelatin) ingrediants as gelleing agent; (CL): Castor leaves-based diet; P: C: Protein to Carbohydrate ratio.
\end{abstract}

\section{Acknowledgements}

The authors wish to express their gratitude to Drs. Andrew Gordon Parker and Carlos Cáceres from FAO/IAEA Division of agriculture and biotechnology laboratory, Seibersdorf, Austria, for helpful discussion of the manuscript.

\section{Authors' contributions}

$A E, Z J, W S$ and $H E$ contributed in the experimental and Conceptualization, AE, WS and HE carried out the bioassay and biological studies. AE, ZJ, HE conducted the biochemical analysis, WS carried out the irradiation treatment and statistical analysis. All authors contributed in the writing of manuscript and approved the final manuscript.

\section{Funding}

This work was partially funded through FAO/IAEA, Division of agriculture and biotechnology laboratory, Seibersdorf, Austria. Foundation within the funding programme, Coordinated Research Project (CRP: D43003) by Contract No. 22147.

\section{Availability of data and materials}

The authors declare that they have no objection to the availability of data and materials.

\section{Declarations}

Ethics approval and consent to participate

Not applicable.

\section{Consent for publication}

Not applicable.

\section{Competing interests}

The authors declare that they have no competing interests.

\section{Author details}

${ }^{1}$ Biological Application Department, Nuclear Research Center, Atomic Energy Authority, Cairo 11787, Egypt. ${ }^{2}$ Department of Economic Entomology and Pesticides, Faculty of Agriculture, Cairo University, Giza, Egypt. ${ }^{3}$ Biology Department, Faculty of Science, Taliban University, Al-Sharm, Yanbu El-Bahr 46420, Kingdom of Saudi Arabia. ${ }^{4}$ Department of Plant Protection, Faculty of Agriculture, Fayoum University, Fayoum, Egypt.

Received: 17 March 2021 Accepted: 23 August 2021

Published online: 27 August 2021

\section{References}

Abbasi BH, Ahmed K, Khalique F, Ayub N, Liu HJ, Kazmi SAR, Aftab MN (2007) Rearing the cotton bollworm, Helicoverpa armigera, on a tapioca-based artificial diet. J Insect Sci 7(1):35

Amer AEA (2015) Economic artificial diets for rearing spiny bollworm, Earias insulana (Boisd.) (Lepidoptera: Noctuidae). J Plant Protec Path 6(3):527-534

Assemila H, Rezapanah M, Vafaei-Shoushtari R, Mehrvar A (2012) Modified artificial diet for rearing of tobacco budworm, Helicoverpa armigera, using the Taguchi method and Derringer's desirability function. J Insect Sci 12(1)
Astuti LP, Rizali A, Firnanda R, Widjayanti T (2020) Physical and chemical properties of flour products affect the development of Tribolium castaneum. $J$ Stored Prod Res 86:101555

Calkins CO, Parker AG (2021) Sterile Insect Technique: Mass rearing for sterile insect release. In: Dyck VA, Hendrichs J, Robinson AS (eds) Sterile insect technique: principles and practice in area-wide. Taylor \& Francis, New York, pp 209-233

Carey JR (2001) Insect Biodemography Ann Rev Entomol 46(1):79-110

Carey JR, Liedo P, Müller HG, Wang JL, Love B, Harshman L, Partridge L (2001) Female sensitivity to diet and irradiation treatments underlies sex-mortality differentials in the mediterranean fruit fly. J Gerontol Ser A Biol Sci Med Sci 56(2):89-93

Chen E, Kolosov D, O'Donnell MJ, Erlandson MA, McNeil JN, Donly C (2018) The effect of diet on midgut and resulting changes in infectiousness of AcMNPV baculovirus in the cabbage looper Trichoplusia Ni. Front Physiol 9:1348

Circu ML, Aw TY (2010) Reactive oxygen species, cellular redox systems, and apoptosis. Free Radical Biol Med 48:749-762

Dyck VA, Hendrichs J, Robinson AS (2021) Sterile insect technique: principles and practice in area-wide integrated pest management. Taylor \& Francis, p 1216

El-Helaly AA, Sayed WA, El-Bendary HM (2020) Impact of emamectin benzoate on nucleopolyhedrosis virus infectivity of Spodoptera littoralis (Boisd) (Lepidoptera: Noctuidae). Egypt J Biol Pest Cont 30(1):1-8

Elmenofy W, Salem R, Osman E, Yasser N, Abdelmawgod A, Saleh M, Zaki A, Hanafy E, Tamim S, Amin S, El-Bakry A (2020) Evaluation of two viral isolates as a potential biocontrol agent against the Egyptian cotton leafworm, Spodoptera littoralis (Boisd.) (Lepidoptera: Noctuidae). Egypt $J$ Biol Pest Cont 30(1):1-8

Finney DJ (1971) Probit analysis, 3rd edn. Cambridge University, Cambridge UK

Hay WT, Behle RW, Berhow MA, Miller AC, Selling GW (2020) Biopesticide synergy when combining plant flavonoids and entomopathogenic baculovirus. Sci Rep 10(1):1-9

Hendrichs J, Robinson AS, Cayol JP, Enkerlin W (2002) Med fly area wide sterile insect technique programs for prevention, suppression or eradication: the importance of mating behavior studies. Florida Entomol 85:1-13

Hoover K, Washburn JO, Volkman LE (2000) Midgut-based resistance of Heliothis virescens to baculovirus infection mediated by phytochemicals in cotton. J Insect Phys 46(6):999-1007

Jiang H, Vilcinskas A, Kanost MR (2010) Immunity in lepidopteran insects. Invertebrate Immun 181-204.

Johnson KS, Felton GW (1996) Physiological and dietary influences on midgut redox conditions in generalist lepidopteran larvae. J Insect Physiol 42:191-198

Lee KP, Raubenheimer D, Behmer ST, Simpson SJ (2003) A correlation between macronutrient balancing and insect hostplant range: evidence from the specialist caterpillar Spodoptera exempta (Walker). Insect Phys 49:1161-1171

Mabrouk A, Bekheit HKM, El-Husseini MM (2001) Economic diet for rearing Spodoptera littoralis (Boisd), used for production of the nuclear polyhedrosis virus. Egypt J Biol Pest Cont 11(2):127-134

Marec F, Vreysen MJ (2019) Advances and challenges of using the sterile insect technique for the management of pest lepidoptera. Insects 10(11):371

Nash WJ, Chapman T (2014) Effect of dietary components on larval life history characteristics in the Medfly (Ceratitis capitata: Diptera, Tephritidae). PLoS ONE 9(1):e86029

Pascacio-Villafán C, Guillén L, Aluja M (2020) Agar and carrageenan as costeffective gelling agents in yeast-reduced artificial diets for mass-rearing fruit flies and their parasitoids. Insects 11(2):131

Povey S, Cotter SC, Simpson SJ, Wilson K (2014) Dynamics of macronutrient self-medication and illness-induced anorexia in virally infected insects. $J$ Animal Ecol 83(1):245-255

Regniere J, Powell J, Bentz B, Nealis V (2012) Effects of temperature on development, survival and reproduction of insects: experimental design, data analysis and modeling. J Insect Physiol 58(5):634-647

Reinecke JP (2013) Nutrition: artificial diets. Compr Insect Physiol Biochem Pharmacol 22:391-419

Sayed WAA, El-Helaly AMA (2018) Effect of gamma irradiation on the susceptibility of the cotton leaf worm, Spodoptera littoralis (Boisd) (Lepidoptera: 
Noctuidae) to the infection with nucleopolyhedrosis virus. Egypt J Biolo Pest Cont 28(1):1-4

Shikano I, Ericsson JD, Cory JS, Myers JH (2010) Indirect plantmediated effects on insect immunity and disease resistance in a tritrophic system. Basic Appl Ecol 11:15-22

Shorey H, Hale RL (1965) Mass rearing of the larvae of nine noctuid species on a simple artificial medium. J Econ Entom 58:522-524

Silva DMD, Bueno ADF, Andrade K, Stecca CDS, Neves PMOJ, Oliveira MCND (2017) Biology and nutrition of Spodoptera frugiperda (Lepidoptera: Noctuidae) fed on different food sources. Scientia Agricola 74(1):18-31 Sorour MA, Khamiss O, El-Wahab ASE, El-Sheikh MAK, Abul-Ela S (2011) An economically modified semi-synthetic diet for mass rearing the Egyptian cotton leaf worm Spodoptera littoralis. Acad J Entom 4(3):118-123

Sun XL, Wang HL, Sun XC, Chen XW, Peng CM, Pan DM, Jehle JA, Van der Werf W, Vlak JM, Hu ZH (2004) Biological activity and field efficacy of a genetically modified Helicoverpa armigera SNPV expressing an insectselective toxin from a chimeric promoter. Biolog Control 29:124-137 Thompson SN, Redak RA (2005) Feeding behaviour and nutrient selection in an insect Manduca sexta $\mathrm{L}$. and alterations induced by parasitism. J Comp Physiol A 191:909-923

Toppozada A, Abdallah S, Eldefrawi ME (1966) Chemosterilization of larvae and adults of the Egyptian cotton leafworm Prodenia litura, by apholate metepa, and tepa. J Econ Entom 59:1125-1128

\section{Publisher's Note}

Springer Nature remains neutral with regard to jurisdictional claims in published maps and institutional affiliations.

\section{Submit your manuscript to a SpringerOpen ${ }^{\circ}$ journal and benefit from:}

- Convenient online submission

- Rigorous peer review

- Open access: articles freely available online

- High visibility within the field

- Retaining the copyright to your article

Submit your next manuscript at $\boldsymbol{\nabla}$ springeropen.com 